\title{
The prognostic value of lactate dehydrogenase levels in colorectal cancer: a meta-analysis
}

\author{
Guanghua $\mathrm{Li}^{\dagger}$, Zhao Wang ${ }^{\dagger}$, Jianbo Xu, Hui Wu, Shirong Cai and Yulong He
}

\begin{abstract}
Background: The prognostic value of lactate dehydrogenase levels in the prognosis of colorectal cancer patients has been assessed for years, although the results remain controversial and heterogeneous. Thus, we comprehensively reviewed the evidence from studies that evaluated lactate dehydrogenase levels in colorectal cancer patients to determine their effect.

Methods: The following databases were searched in September 2014 to identify studies that evaluated the prognostic value of lactate dehydrogenase levels in colorectal cancer: PubMed, EMBASE, and the Cochrane Central Register of Controlled Trials. We extracted hazard ratios (HRs) and the associated $95 \%$ confidence intervals (Cls) from the identified studies, and performed random-effects model meta-analyses on the overall survival (OS) and progression-free survival (PFS). Thirty-two studies with a cumulative sample size of 8,261 patients were included in our analysis.

Results: Our meta-analyses revealed that high levels of lactate dehydrogenase were associated with poor OS $(\mathrm{HR}, 1.75 ; 95 \% \mathrm{Cl}, 1.52-2.02)$ in colorectal cancer patients. However, this effect was not obvious in the OS of nonmetastatic colorectal cancer patients ( $\mathrm{HR}, 1.21 ; 95 \% \mathrm{Cl}, 0.79-1.86)$. The prognostic value of lactate dehydrogenase levels on PFS was also not confirmed (HR, 1.36; $95 \% \mathrm{Cl}, 0.98-1.87)$. Subgroup analyses revealed that the prognostic significance of lactate dehydrogenase was independent of study location, patient age, number of patients, metastasis, chemotherapy with anti-angiogenesis drugs, study type, or risk of bias.
\end{abstract}

Conclusions: Our results indicate that high lactate dehydrogenase levels are associated with poor OS among colorectal cancer patients, although these levels are not significant predictors of PFS.

Keywords: Lactate dehydrogenase, Colorectal cancer, Prognosis, Meta-analysis

\section{Background}

Colorectal cancer (CRC) represents the third most common malignancy throughout the world [1]. The prognosis for late stage CRC is extremely poor, and survival is often measured in months once metastases are present. Moreover, despite the fact that advances in modern systemic therapies for CRC have resulted in improved survival, the failure rate in the adjuvant setting is $30 \%$ for high risk Stage II and Stage III patients, and the overall response rate is only $60 \%$ for patients with Stage

\footnotetext{
* Correspondence: Igh8711@126.com

${ }^{\dagger}$ Equal contributors

Department of Gastrointestinal Surgery, First Affiliated Hospital of Sun Yat-sen University, 510080 Guangzhou, Guangdong Province, People's Republic of China
}

IV CRC [2, 3]. Therefore, it is necessary to discover biomarkers that can identify patients that are at-risk for disease recurrence and survival.

Cancer cells rely heavily on aerobic glycolysis to support their growth, a process that is known as the Warburg effect $[4,5]$. Lactate dehydrogenase plays an important role in this process by mediating the conversion of pyruvate and lactate, and this enzyme is an emerging anticancer target [6]. In addition, elevated lactate dehydrogenase levels are consistently reported as a prognostic factor for poor survival among several cancer groups [7]. The authors conducted a prospective study, including various cancer types (liver, lung, bone, brain etc.), symptoms, signs and other serological variables, to evaluate LDH's value as 
a predictor of survival time in terminal cancer patients. Their results demonstrated that serum LDH level was significantly associated with survival time $(\mathrm{HR}=2.087$, $P=0.002$ ) in patients with terminal cancer [7]. Although a large number of studies have been performed among patients with CRC, the prognostic value of lactate dehydrogenase levels among CRC patients remains controversial. Thus, we conducted this meta-analysis to evaluate the prognostic value of lactate dehydrogenase levels among CRC patients.

\section{Methods}

\section{Search strategy and selection criteria}

The following databases were searched in September 2014: PubMed, EMBASE, and the Cochrane Central Register of Controlled Trials. In addition, we examined the reference lists of relevant articles and review articles. No language restrictions or time limits were applied to the initial search. Search strategies, databases, and date ranges are provided in the supplemental material (Additional file 1). Eligibility criteria for inclusion in this meta-analysis were: [1] the study evaluated the correlation between lactate dehydrogenase levels and survival among CRC patients, [2] the study provided sufficient information for the estimation of hazard ratios (HRs) and their $95 \%$ confidence intervals (CIs), and [3] the study was published in English, German, or French. Two reviewers (L.G.H. and W.Z.) independently screened the identified abstracts for eligibility, and disagreements were resolved by discussion. When multiple publications reported identical or overlapping patient cohorts (e.g., same authors, institutions), only the most informative study was included in the analysis.

\section{Data extraction}

Two investigators (L.G.H. and W.Z.) independently extracted the following data from the eligible articles: first author, year of publication, study location, sample size, patient age, site of disease, stage of disease, Lactate dehydrogenase cut-off value, use of adjuvant chemotherapy, prognostic outcomes, use of multivariate models, and study type.

\section{Study quality assessment}

The quality of the included studies was assessed using the modified risk of bias tool that is recommended by the Cochrane Collaboration, as previously described $[8,9]$. Briefly, the criteria in Additional file 2 were used to assess the risk of bias of included studies. Each question is answered with "Yes" (indicating low risk of bias), "No" (indicating high risk of bias), and "Unclear" (indicating unclear or unknown risk of bias). The summary assessment of the risk of bias for the individual studies was carried out as follows: 1 . Low risk of bias: Low risk of bias for all domains. 2.Unclear risk of bias: Unclear risk of bias for one or more domains. 3. High risk of bias: High risk of bias for one or more domains.

\section{Statistical analyses}

The prognostic value of lactate dehydrogenase levels for survival was measured using HRs. If an $H R$ and the associated standard error or CI was not reported, we approximated the HR using the statistical data that was provided in the article (e.g., individual patient data or survival plots) $[10,11]$. The extracted HRs were pooled using a fixed-effects model (weighted with inverse variance) or a random-effects model [12]. Our method consisted of using the fixed-effects model with an assumption of homogeneity in the individual HRs. Heterogeneity between studies was assessed using the $\chi^{2}$ and $\mathrm{I}^{2}$ statistics. If the assumption of homogeneity was rejected, the random-effects model was used [13].

$\mathrm{HR}>1$ indicated a worsened prognosis in the high lactate dehydrogenase group, and a minimum of 3 studies was required to perform the meta-analyses. Sensitivity analysis was also conducted using sequential omission of individual studies to evaluate the stability of the results. Funnel plot analyses were used to evaluate publication bias [14]. All analyses were performed using STATA version 10.0, and a $p$-value $<0.05$ was considered statistically significant.

\section{Results}

\section{Baseline study characteristics}

We identified 32 eligible studies with a cumulative sample size of 8,261 patients (Fig. 1) [15-47]. The median study sample size was 157 patients (range, 31-855 patients), and all eligible studies were published between 1988 and 2014 (Table 1). Thirteen studies were excluded owing to the inclusion of a patient cohort that was also used in the other selected studies (studies that were excluded and included were [24, 48-59]). The extracted variables from the included studies are summarized in Table 1 (Abbreviations: FOLFOX, infusional fluorouracil, leucovorin, and oxaliplatin; FU, fluorouracil; IHC, immunohistochemistry; RCT, randomized controlled trial; NR, not reported; RMCS, retrospective multicenter cohort study; PSCS, prospective single-center cohort study; RSCS, retrospective single-center cohort study).

Among the 32 studies that used serum lactate dehydrogenase levels to investigate their influence on patient prognosis, 2 studies $[29,30]$ used an immunohistochemistry method, and 1 study [30] used serum levels and immunohistochemistry methods. Twelve studies were graded with a low risk of bias (Additional file 2). Our analysis of lactate dehydrogenase levels as a prognostic factor was confirmed by the multivariate analysis in 19 of the included studies [16, 17, 19-23, 25, 27, 28, 30, 32, $34,35,38,40-43]$. An HR for overall survival (OS) and 


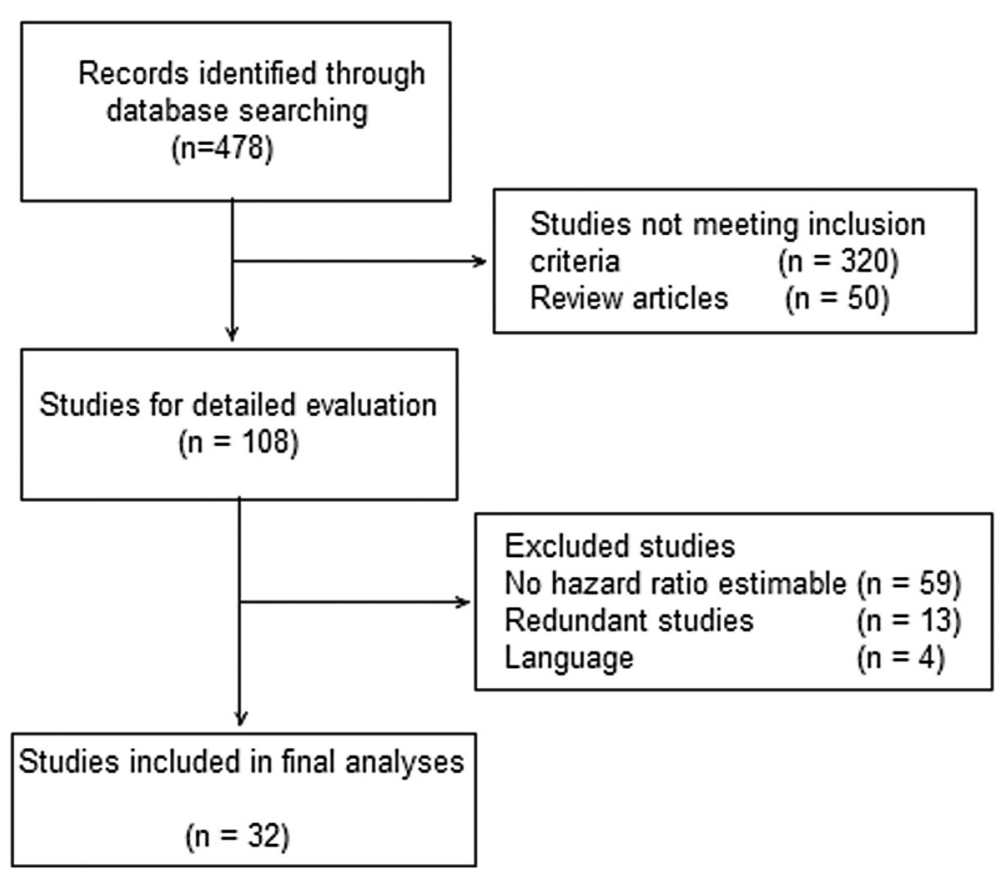

Fig. 1 Flow chart for the study selection

progression-free survival (PFS) was extracted from 27 and 8 studies, respectively. Funnel plot analyses did not reveal a significant publication bias regarding the analyzed outcomes (Additional file 3: Figure S1). However, the funnel plot B (PFS) does not allow to exclude a publication bias, because of limited number of studies.

\section{The prognostic value of lactate dehydrogenase levels}

Pooled analysis of OS in all studies using the random effects model revealed a significant prognostic value for lactate dehydrogenase levels in CRC patients (HR, 1.75; $95 \%$ CI, $1.52-2.02 ; n=27 ; \mathrm{I}^{2}=66.5 \%$; Fig. 2a). Sensitivity analyses revealed that heterogeneity was not caused by any one study. However, our meta-analyses using the random effects model did not confirm the prognostic value for lactate dehydrogenase levels in predicting PFS (HR, 1.36; 95 \% CI, 0.98-1.87; $n=8$; $\mathrm{I}^{2}=87$ \%; Fig. 2b), and we observed a significant degree of heterogeneity. This heterogeneity could not be reduced substantially by the exclusion of any one study.

\section{Subgroup analyses}

Despite the limited number of included studies, the subgroup analyses of lactate dehydrogenase levels and survival were performed to thoroughly explore the results. We performed meta-regression and subgroup analysis of lactate dehydrogenase levels on OS according to study location, patient age, number of patients, metastasis, chemotherapy with anti-angiogenesis drugs, study type, and risk of bias. The results revealed that none of the investigated factors had a significant association with the heterogeneity (Table 2). However, subgroup analysis indicated a significant relation between high lactate dehydrogenase levels and reduced OS among metastatic CRC patients (HR, 1.96; $95 \% \mathrm{CI}, 1.61-2.37)$, although this effect was not significant among non-metastatic patients (HR, 1.21; $95 \%$ CI, 0.79-1.86; Table 2). The effect of $\mathrm{LDH}$ on OS among different cutoffs for $\mathrm{LDH}$ is also shown in Table 2. The HRs were 1.93 (95\% CI 1.50 to 2.49) for $\mathrm{LDH}$ cutoff $>300 \mathrm{U} / \mathrm{L}, 1.84 .(95 \%$ CI 1.08 to 3.13) for LDH cutoff 250 to 300U/L and 1.44 (95\% CI 0.94 to 2.21 ) for LDH cutoff $<250 \mathrm{U} / \mathrm{L}$. There was no statistically significant heterogeneity between the different cutoffs for LDH (P for subgroup difference $=0.309$ ). Our results suggest that relation between high lactate dehydrogenase levels and reduced OS among metastatic CRC patients disappears if the LDH cutoff value less than 250U/L (HR, 1.44; $95 \%$ CI 0.94 to 2.21 ).

Subgroup analysis of the other factors did not alter the significant prognostic value of lactate dehydrogenase levels in predicting OS.

We also performed meta-regression and subgroup analysis of lactate dehydrogenase levels and PFS. Owing to the limited number of included studies, only study location, number of patients, chemotherapy with anti-angiogenesis drugs, and risk of bias were explored. The results revealed that none of the investigated factors had a significant association with the heterogeneity (Table 3 ). Moreover, subgroup analysis revealed no relationship between lactate dehydrogenase levels and PFS among CRC patients. 
Table 1 Baseline characteristics of included studies

\begin{tabular}{|c|c|c|c|c|c|c|c|c|c|c|c|c|c|}
\hline \multirow[b]{2}{*}{ First author } & \multirow[b]{2}{*}{ Year } & \multirow[b]{2}{*}{ Country } & \multicolumn{3}{|c|}{ Sample size } & \multicolumn{2}{|l|}{ Age } & \multirow[b]{2}{*}{ Tumor stage } & \multicolumn{2}{|l|}{$\mathrm{LDH}$} & \multirow[b]{2}{*}{ Adjuvant chemotherapy } & \multirow[b]{2}{*}{ Suvival analysis } & \multirow[b]{2}{*}{$\begin{array}{l}\text { Outcome } \\
\text { report }\end{array}$} \\
\hline & & & Total & Colon & Rectum & Median & Range & & Cutoff & $\begin{array}{l}\text { Detection } \\
\text { method }\end{array}$ & & & \\
\hline Agrawal & 2013 & USA & 146 & NR & NR & NR & $<=50$ & IV & $200 U / L$ & serum & NR & Univariate & OS \\
\hline Alonso-Espinaco & 2014 & Spanish & 157 & NR & NR & NR & $28-82$ & $\mathrm{mCRC}$ & NR & serum & FOLFOX/XELOX & Univariate Multivariate & OS PFS \\
\hline Asmis & 2011 & Canada & 544 & NR & $N R$ & NR & NR & $N R$ & NR & serum & Cetuximab-based & Univariate Multivariate & OS \\
\hline Caputo & 2014 & Italy & 96 & 88 & 6 & NR & $18-80$ & T2T3T4/M0 & $248 U / L$ & serum & NO & Univariate & OS PFS \\
\hline Cetin & 2012 & Turkey & 168 & NR & NR & NR & NR & $\mathrm{mCRC}$ & NR & serum & anti-VEGF therapy & Multivariate & OS \\
\hline Chibaudel & 2011 & France & 535 & 349 & 177 & 65 & $29-80$ & $\mathrm{mCRC}$ & NR & serum & $\begin{array}{l}\text { Oxaliplatin-Based or Irinotecan- } \\
\text { Based First-Line Chemotherapy }\end{array}$ & Univariate Multivariate & OS \\
\hline Diouf & 2014 & France & 620 & 398 & 211 & NR & $18-80$ & $\mathrm{mCRC}$ & NR & serum & FOLFOX4 or FOLFOX7 & Univariate Multivariate & OS \\
\hline Formica & 2013 & Italy & 31 & 26 & 5 & 69 & $41-83$ & mCRC & $245 U / L$ & serum & FOLFORIN + bevacizumab & Multivariate & PFS \\
\hline Galizia & 2008 & Italy & 65 & 53 & 12 & NR & $28-84$ & $\begin{array}{l}\text { IV with liver } \\
\text { metastasis }\end{array}$ & $450 U / L$ & serum & $\begin{array}{l}\text { fluorouracil, folinic and acid, and } \\
\text { oxaliplatin/irinotecan }\end{array}$ & Multivariate & OS \\
\hline Giessen & 2013 & German & 215 & 136 & 79 & 61.8 & $32-78$ & $\begin{array}{l}\mathrm{mCRC} / \text { liver } \\
\text { metastas }\end{array}$ & $250 U / L$ & serum & FUFURI or mIROX & Multivariate & OS \\
\hline Giessen & 2014 & Italy & 249 & 0 & 249 & 64.6 & $30.6-90.7$ & $|-|||$ & 171 & serum & $\begin{array}{l}\text { Chemotherapy/Radiotherapy/ } \\
\text { Concomitant chemoradiotherapy }\end{array}$ & Univariate & OS \\
\hline Hannisdal & 1994 & Norway & 100 & 0 & 100 & 69 & $33-87$ & $\begin{array}{l}\text { Local regional } \\
\text { relapse } \pm \text { metastasis }\end{array}$ & 500 & serum & chemoradiotherapy & Multivariate & OS \\
\hline $\mathrm{He}$ & 2013 & China & 239 & 171 & 68 & 57 & $18-83$ & mCRC & $245 U / L$ & serum & Folfox/Xelox/Folfiri/Xeliri & Multivariate & OS \\
\hline Koukourakis & 2006 & UK & 128 & 78 & 50 & 67 & $41-88$ & Dukes $B, C, D$ & NR & $\mathrm{IHC}$ & NO & Univariate & OS \\
\hline Koukourakis & 2011 & Greece & 179 & NR & NR & NR & $28-83$ & $\mathrm{mCRC}$ & NR & serum $I H C$ & FOLFOX4 + vatalanib/placebo & Univariate Multivariate & OS \\
\hline Lin & 2006 & USA & 66 & NR & NR & 62 & $30-86$ & $\mathrm{mCRC}$ & 618 & serum & XCEL \pm Radiation & Univariate & OS \\
\hline Lin & 2005 & China & 45 & 34 & 11 & 32 & $18-39$ & Dukes $B, C, D$ & 230 & serum & 5-FU based chemotherapy & Multivariate & OS \\
\hline Machida & 2008 & Japan & 103 & 66 & 37 & 62 & $29-80$ & $\mathrm{mCRC}$ & 300 & serum & LV-modulated 5-FU/irinotecan + 5-FU & Univariate & OS \\
\hline Maurel & 2007 & Spain & 120 & NR & NR & 66 & $33-82$ & $\mathrm{mCRC}$ & 450 & serum & 5-FU + oxaliplatin/irinotecan & Multivariate & OS \\
\hline Mekenkam & 2012 & Netherland & 803 & 538 & 260 & 63 & $27-84$ & $\begin{array}{l}\text { Advanced stage } \\
\text { (curative surgery) }\end{array}$ & NR & serum & $\begin{array}{l}\text { capecitabine, irinotecan, oxaliplatin: } \\
\text { Sequential VS Combination }\end{array}$ & Multivariate & OS \\
\hline
\end{tabular}


a

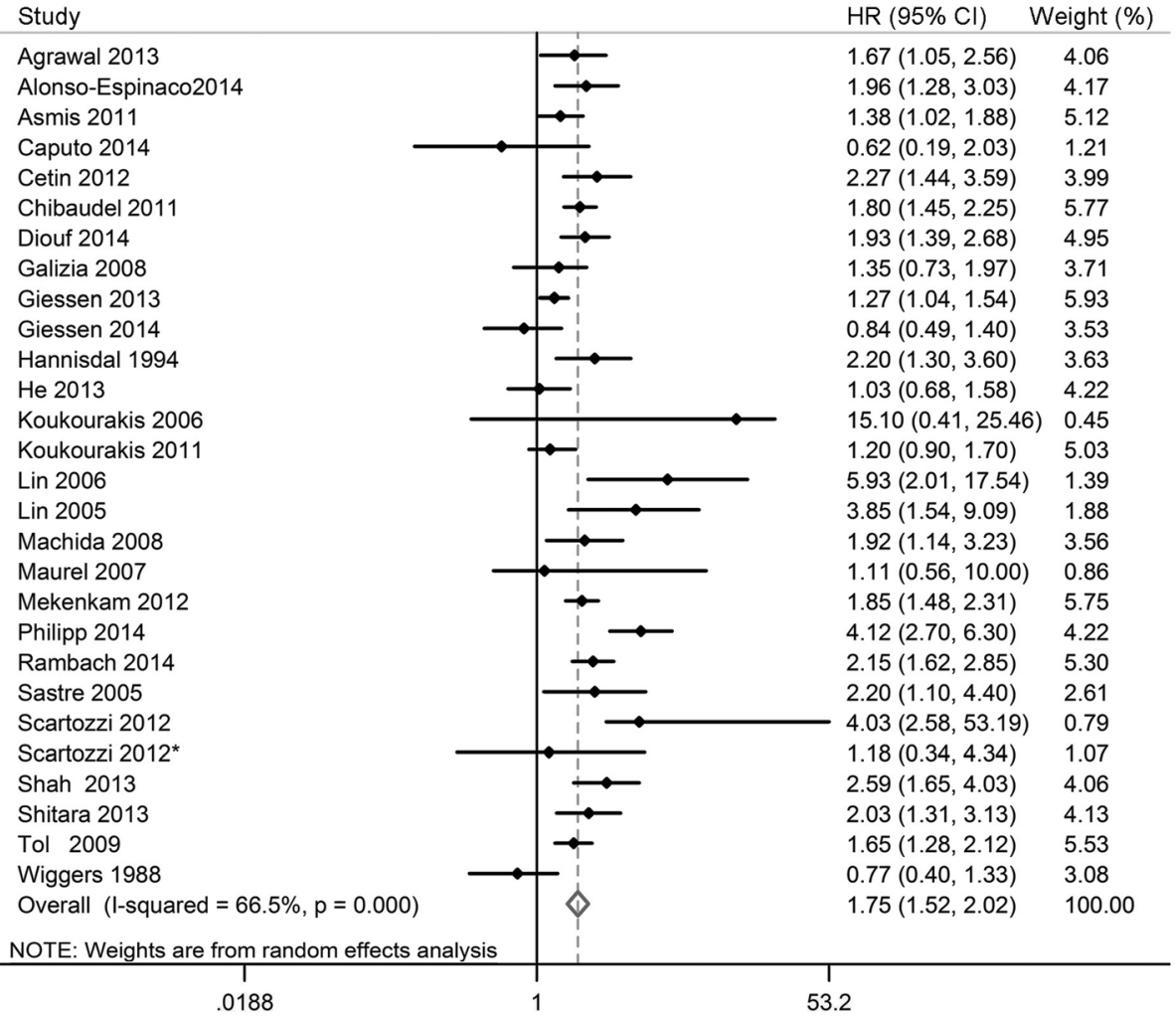

b

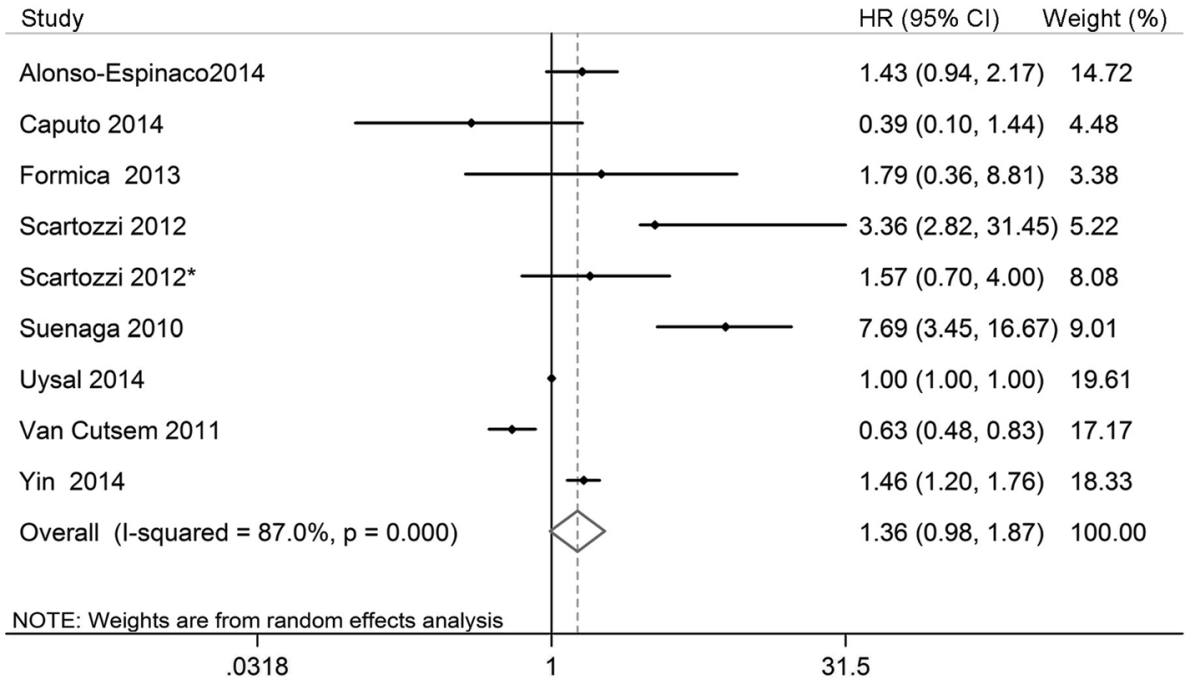

Fig. 2 Meta-analyses of the association between lactate dehydrogenase levels and (a) overall survival or (b) progression-free survival. Squares and horizontal bars indicate the point estimates (HRs) with $95 \%$ Cls for each individual study. Diamonds indicate the summary estimates for the hazard ratio. The width of the diamond corresponds to the $95 \% \mathrm{Cl}$

\section{Discussion}

This systematic review and meta-analysis revealed that high lactate dehydrogenase levels are associated with poor OS among patients with CRC. However, this prognostic value was not observed for PFS among CRC patients.

Despite the number of studies that have been conducted in this field, the prognostic value of lactate 
Table 2 Stratified analysis of pooled hazard ratios of lactate dehydrogenase on overall survival

\begin{tabular}{|c|c|c|c|c|c|c|c|}
\hline \multirow[b]{2}{*}{ Stratified analysis } & \multirow[b]{2}{*}{ No. of studies } & \multirow[b]{2}{*}{ No. of patients } & \multicolumn{2}{|c|}{ Pooled HR (95 \% Cl) } & \multirow[b]{2}{*}{$\begin{array}{l}\text { Meta-regression } \\
\text { on } p \text {-value }\end{array}$} & \multicolumn{2}{|c|}{ Heterogeneity } \\
\hline & & & Fixed & Random & & $\mathrm{I}^{2}(\%)$ & $\overline{p \text {-value }}$ \\
\hline Study location & & & & & 0.581 & & \\
\hline Asia & 4 & 580 & $1.66[1.29,2.14]$ & $1.82[1.14,2.9]$ & & 67.9 & 0.025 \\
\hline Europe & 19 & 5276 & $1.66[1.53,1.80]$ & $1.67[1.40,2.0]$ & & 69.5 & $<0.001$ \\
\hline Other regions & 5 & 1065 & $1.85[1.52,2.25]$ & $2.07[1.45,2.94]$ & & 64.1 & 0.025 \\
\hline Age & & & & & 0.563 & & \\
\hline$\leq 50$ & 2 & 191 & $1.98[1.33,2.94]$ & $2.31[1.04,5.13]$ & & 63.1 & 0.1 \\
\hline No limitation & 22 & 5623 & $1.70[1.57,1.84]$ & $1.77[1.51,2.08]$ & & 68.5 & $<0.001$ \\
\hline Number of patients & & & & & 0.68 & & \\
\hline$\geq 100$ & 22 & 6428 & $1.68[1.56,1.81]$ & $1.73[1.49,2.01]$ & & 69 & $<0.001$ \\
\hline$<100$ & 6 & 439 & $1.84[1.66,2.04]$ & $1.96[1.11,3.43]$ & & 60.3 & 0.28 \\
\hline Metastasis & & & & & 0.059 & & \\
\hline Yes & 16 & 5044 & $1.84[1.66,2.04]$ & $1.96[1.61,2.37]$ & & 64.4 & $<0.001$ \\
\hline No & 5 & 883 & $1.53[1.29,1.82]$ & $1.21[0.79,1.86]$ & & 74.4 & 0.028 \\
\hline LDH cutoff & & & & & 0.309 & & \\
\hline$>300 \mathrm{U} / \mathrm{L}$ & 7 & 764 & $1.93[1.50,2.49]$ & $1.98[1.41,2.77]$ & & 29.1 & 0.206 \\
\hline 250-300 U/L & 5 & 1028 & $1.61[1.38,1.88]$ & $1.84[1.08,3.13]$ & & 88.6 & $<0.001$ \\
\hline$<250 \mathrm{U} / \mathrm{L}$ & 6 & 1174 & $1.58[1.31,1.90]$ & $1.44[0.94,2.21]$ & & 75.4 & 0.001 \\
\hline $\begin{array}{l}\text { Chemotherapy with } \\
\text { anti-angiogenesis drugs }\end{array}$ & & & & & 0.64 & & \\
\hline Yes & 5 & 1675 & $1.75[1.51,2.02]$ & $1.78[1.41,2.23]$ & & 57.3 & 0.053 \\
\hline No & 16 & 4166 & $1.60[1.46,1.75]$ & $1.65[1.40,1.94]$ & & 54.8 & 0.003 \\
\hline Study type & & & & & 0.863 & & \\
\hline non- $R C^{a}$ & 22 & 3683 & $1.66[1.51,2.02]$ & $2.03[1.31,3.13]$ & & 71.5 & $<0.001$ \\
\hline $\mathrm{RCT}$ & 5 & 3238 & $1.73[1.54,1.94]$ & $1.73[1.54,1.94]$ & & $<0.01$ & 0.535 \\
\hline Risk of bias & & & & & 0.31 & & \\
\hline High & 16 & 3142 & $1.52[1.36,1.68]$ & $1.63[1.28,2.09]$ & & 76.5 & $<0.001$ \\
\hline Low & 11 & 3799 & $1.87[1.69,2.07]$ & $1.65[1.28,2.12]$ & & $<0.01$ & 0.655 \\
\hline
\end{tabular}

${ }^{a}$ non-RCT includes PSCS, RMCS and RSCS groups

dehydrogenase levels among CRC patients has remained highly uncertain, given the inconsistent results from the previous studies. In the present study, pooled analyses of the available data revealed a significant association between high lactate dehydrogenase levels and poorer OS. However, there was insufficient statistical power to detect this association among patients with non-metastatic disease (Pooled HR1.21, 95 \% CI [0.79, 1.86]).

There is recent evidence that the addition of antiangiogenesis medication diminishes the impact of lactate dehydrogenase expression on the prognosis of CRC patients [30]. Besides, recent research reveals that high $\mathrm{LDH}$ is a significant indicator of bevacizumab-based chemotherapy-induced response to treatment for previously untreated metastatic colorectal cancer patients
[60]. However, our meta-analysis did not detect a similar effect among CRC patients. This discrepancy may be attributed to the different kinds of anti-angiogenesis medications that were used in the previous study. Combined with the different dose that was employed for the anti-angiogenesis medications, there was insufficient statistical power to detect any differences in the survival of CRC patients $(p=0.64)$. However, our data supports the approach to aggregate results from the available studies regarding the prognostic significance of anti-angiogenesis drugs in CRC.

Interestingly, we detected significant heterogeneity among the studies that were included in this systematic review. However, sensitivity analysis did not identify the source of this heterogeneity. We did observe a wide 
Table 3 Stratified analysis of pooled harazd ratios of lactate dehydrogenase on progression free survival

\begin{tabular}{|c|c|c|c|c|c|c|c|}
\hline \multirow[b]{2}{*}{ Stratified analysis } & \multirow[b]{2}{*}{ No. of studies } & \multirow[b]{2}{*}{ No. of patients } & \multicolumn{2}{|l|}{ Pooled HR (95 \% Cl) } & \multirow[b]{2}{*}{ Meta-regression on $p$-value } & \multicolumn{2}{|c|}{ Heterogeneity } \\
\hline & & & Fixed & Random & & $\overline{1^{2}(\%)}$ & $p$-value \\
\hline Study location & & & & & 0.196 & & \\
\hline Asia & 2 & 418 & $1.60[1.33,1.93]$ & $3.20[0.63,16.27]$ & & 93.8 & $<0.001$ \\
\hline Europe & 6 & 1359 & $0.87[0.71,1.08]$ & $1.15[0.65,2.04]$ & & 74.4 & 0.002 \\
\hline Number of patients & & & & & 0.762 & & \\
\hline$\geq 100$ & 4 & 1483 & $1.16[1.00,1.34]$ & $1.26[0.72,2.19]$ & & 89.5 & $<0.001$ \\
\hline$<100$ & 5 & 330 & $1.00[1.001,1.004]$ & $1.59[0.64,3.98]$ & & 86.3 & $<0.002$ \\
\hline $\begin{array}{l}\text { Chemotherapy with } \\
\text { anti-angiogenesis drugs }\end{array}$ & & & & & 0.717 & & \\
\hline Yes & 6 & 1422 & $1.00[1.001,1.004]$ & $1.36[0.96,1.98]$ & & 90.6 & $<0.001$ \\
\hline No & 2 & 295 & $1.56[1.06,2.33]$ & $1.80[0.86,3.80]$ & & 41.9 & 0.19 \\
\hline Risk of bias & & & & & 0.805 & & \\
\hline High & 6 & 738 & $1.00[1.001,1.004]$ & $1.51[1.01,2.25]$ & & 89.1 & $<0.001$ \\
\hline Low & 3 & 1075 & $0.74[0.57,0.95]$ & $1.31[0.49,3.53]$ & & 805 & 0.006 \\
\hline
\end{tabular}

range in the cut-off levels for lactate dehydrogenase; therefore, additional standardization should be addressed in the design of future studies, thereby enhancing the utility of their results. Most of the studies that we included focused on metastatic CRC patients, which could also be a source of bias. In addition, our approach of extrapolating the HRs from the survival plots might be another potential source of bias. Although we extracted the survival rates from survival curve graphs using Engauge software, this approach did not completely eliminate inaccuracies during the extraction of the survival rates. Moreover, the language of publication may have added additional bias, as the present review was restricted to articles published in English, German, or French, as other languages were not accessible for the readers. This bias could favor positive studies, which are more frequently published in English, as negative studies tend to be published in the authors' native languages.

\section{Conclusions}

In conclusion, there is evidence that high lactate dehydrogenase levels indicate poor prognosis among CRC patients. However, subgroup analysis revealed no such prognostic value among non-metastatic CRC patients. These findings should encourage efforts to identify subpopulations with high lactate dehydrogenase levels that might put metastatic patients at a particular risk of poor survival.

\section{Availability of data and materials}

The datasets supporting the conclusions of this article are included within the article and its additional files.

\section{Additional files}

Additional file 1: Search strategies. (DOCX $14 \mathrm{~kb}$ )

Additional file 2: Assessment of risk of bias. (XLSX $11 \mathrm{~kb}$ )

Additional file 3: Figure S1. Funnel plot analyses of studies report OS (A) and PFS (B). (JPEG $1290 \mathrm{~kb}$ )

\section{Abbreviations}

CRC: Colorectal cancer; OS: Overall survival; PFS: progression free survival.

\section{Competing interests}

No competing interests exit in the submission of this manuscript, and manuscript is approved by all authors for publication. All authors have contributed significantly, and are in agreement with the content of the manuscript.

\section{Authors' contributions}

LGH and WZ extracted the data from literature; XJB and WH performed analysis; CSR and HYL designed the project. All authors read and approved the final manuscript.

\section{Grant support}

This work was not supported by any fund.

Received: 22 March 2015 Accepted: 13 March 2016

Published online: 25 March 2016

\section{References}

1. Jemal A, Siegel R, Xu J, Ward E. Cancer statistics, 2010. CA Cancer J Clin. 2010;60(5):277-300.

2. Galizia G, Gemei M, Del Vecchio L, Zamboli A, Di Noto R, Mirabelli P, et al. Combined CD133/CD44 expression as a prognostic indicator of disease-free survival in patients with colorectal cancer. Arch Surg. 2012;147(1):18-24.

3. Wolpin BM, Meyerhardt JA, Mamon HJ, Mayer RJ. Adjuvant treatment of colorectal cancer. CA Cancer J Clin. 2007;57(3):168-85.

4. Ward PS, Thompson CB. Metabolic reprogramming: a cancer hallmark even warburg did not anticipate. Cancer Cell. 2012;21(3):297-308.

5. Vander Heiden MG, Cantley LC, Thompson CB. Understanding the Warburg effect: the metabolic requirements of cell proliferation. Science. 2009;324(5930):1029-33. 
6. Doherty JR, Cleveland JL. Targeting lactate metabolism for cancer therapeutics. J Clin Invest. 2013;123(9):3685-92.

7. Suh SY, Ahn HY. Lactate dehydrogenase as a prognostic factor for survival time of terminally ill cancer patients: a preliminary study. Eur J Cancer. 2007:43(6):1051-9.

8. Higgins JP GS. Cochrane Handbook for Systematic Reviews of Interventions Version 5.0.2 [updated September 2009]. Cochrane Collaboration 2009.

9. Rahbari NN, Aigner M, Thorlund K, Mollberg N, Motschall E, Jensen K, et al. Metaanalysis shows that detection of circulating tumor cells indicates poor prognosis in patients with colorectal cancer. Gastroenterology. 2010;138(5):1714-26.

10. Parmar MK, Torri V, Stewart L. Extracting summary statistics to perform meta-analyses of the published literature for survival endpoints. Stat Med. 1998;17(24):2815-34

11. Tierney JF, Stewart LA, Ghersi D, Burdett S, Sydes MR. Practical methods for incorporating summary time-to-event data into meta-analysis. Trials. 2007;8:16.

12. DerSimonian R, Laird N. Meta-analysis in clinical trials. Control Clin Trials. 1986:7(3):177-88.

13. Lau J, loannidis JP, Schmid CH. Quantitative synthesis in systematic reviews. Ann Intern Med. 1997;127(9):820-6.

14. Egger M, Davey Smith G, Schneider M, Minder C. Bias in meta-analysis detected by a simple, graphical test. BMJ. 1997:315(7109):629-34.

15. Agrawal K, Jain S, Pattali S, Singh A, Agrawal K, Cleveland B, et al. Factors affecting overall survival in a minority-based population of young colorectal cancer patients: A single-institution multivariate analysis. Am J Gastroenterol. 2013;108:S628.

16. Alonso-Espinaco V, Cuatrecasas M, Alonso V, Escudero P, Marmol M,

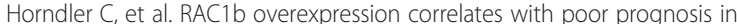
KRAS/BRAF WT metastatic colorectal cancer patients treated with first-line FOLFOX/XELOX chemotherapy. Eur J Cancer. 2014;50(11):1973-81.

17. Asmis TR, Powell E, Karapetis CS, Jonker DJ, Tu D, Jeffery M, et al. Comorbidity, age and overall survival in cetuximabtreated patients with advanced colorectal cancer (ACRC)-results from NCIC CTG CO.17: A phase III trial of cetuximab versus best supportive care. Ann Oncol. 2011;22(1):118-26.

18. Caputo D, Caricato M, Vincenzi B, La Vaccara V, Masciana G, Coppola R. Serum lactate dehydrogenase alone is not a helpful prognostic factor in resected colorectal cancer patients. Updates Surg. 2014;66(3):211-5. doi:10.1007/s13304-014-0260-5. Epub 2014 Aug 8.

19. Cetin B, Kaplan MA, Berk V, Ozturk SC, Benekli M, Isikdogan A, et al. Prognostic factors for overall survival in patients with metastatic colorectal carcinoma treated with vascular endothelial growth factor-targeting agents. Asian Pac J Cancer Prev. 2012;13(3):1059-63.

20. Chibaudel B, Bonnetain F, Tournigand C, Bengrine-Lefevre L, Teixeira L, Artru $P$, et al. Simplified prognostic model in patients with oxaliplatin-based or irinotecan-based first-line chemotherapy for metastatic colorectal cancer: a GERCOR study. In: Oncologist; 2011. p. 1228-38.

21. Diouf M, Chibaudel B, Filleron T, Tournigand C, Hug de Larauze M, GarciaLarnicol ML, et al. Could baseline health-related quality of life (QoL) predict overall survival in metastatic colorectal cancer? The results of the GERCOR OPTIMOX 1 study. Health Qual Life Outcomes. 2014;12(1):69.

22. Formica V, Cereda V, Di Bari MG, Grenga I, Tesauro M, Raffaele P, et al. Peripheral CD45RO, PD-1, and TLR4 expression in metastatic colorectal cancer patients treated with bevacizumab, fluorouracil, and irinotecan (FOLFIRI-B). Med Oncol. 2013;30(4):743.

23. Galizia G, Lieto E, Orditura M, Castellano P, Imperatore V, Pinto M, et al. First-line chemotherapy vs bowel tumor resection plus chemotherapy for patients with unresectable synchronous colorectal hepatic metastases. Arch Surg. 2008;143(4):352-8.

24. Giatromanolaki A, Koukourakis MI, Sivridis E, Gatter KC, Trarbach T, Folprecht $\mathrm{G}$, et al. Vascular density analysis in colorectal cancer patients treated with vatalanib (PTK787/ZK222584) in the randomised CONFIRM trials. Br J Cancer. 2012;107(7):1044-50. doi:10.1038/bjc.2012.369. Epub 2012 Aug 21.

25. Giessen C, Fischer Von Weikersthal L, Laubender RP, Stintzing S, Modest DP, Schalhorn A, et al. Evaluation of prognostic factors in liver-limited metastatic colorectal cancer: A preplanned analysis of the FIRE-1 trial. $\mathrm{Br} J$ Cancer. 2013;109(6):1428-36.

26. Giessen C, Nagel D, Glas M, Spelsberg F, Lau-Werner U, Modest DP, et al. Evaluation of preoperative serum markers for individual patient prognosis in stage I-III rectal cancer. Tumor Biology. 2014;35(10):10237.

27. Hannisdal E, Tveit KM, Theodorsen L, Host H. Host markers and prognosis in recurrent rectal carcinomas treated with radiotherapy. Acta Oncol. 1994;33(4):415-21.
28. He WZ, Guo GF, Yin CX, Jiang C, Wang F, Qiu HJ, et al. Gamma-glutamyl transpeptidase level is a novel adverse prognostic indicator in human metastatic colorectal cancer. Color Dis. 2013;15(8):e443-52.

29. Koukourakis Ml, Giatromanolaki A, Sivridis E, Gatter KC, Harris AL. Lactate dehydrogenase 5 expression in operable colorectal cancer: strong association with survival and activated vascular endothelial growth factor pathway-a report of the Tumour Angiogenesis Research Group. J Clin Oncol. 2006;24(26):4301-8. Epub 2006 Aug 8.

30. Koukourakis MI, Giatromanolaki A, Sivridis E, Gatter KC, Trarbach T, Folprecht $\mathrm{G}$, et al. Prognostic and predictive role of lactate dehydrogenase 5 expression in colorectal cancer patients treated with PTK787/ZK 222584 (Vatalanib) antiangiogenic therapy. Clin Cancer Res. 2011;17(14):4892-900.

31. Lin EH, Curley SA, Crane CC, Feig B, Skibber J, Delcos M, et al. Retrospective study of capecitabine and celecoxib in metastatic colorectal cancer: Potential benefits and COX-2 as the common mediator in pain, toxicities and survival? Am J Clin Oncol. 2006;29(3):232-9.

32. Lin JT, Wang WS, Yen CC, Liu JH, Yang MH, Chao TC, et al. Outcome of colorectal carcinoma in patients under 40 years of age. J Gastroenterol Hepatol. 2005:20(6):900-5.

33. Machida N, Yoshino T, Boku N, Hironaka S, Onozawa Y, Fukutomi A, et al. Impact of baseline sum of longest diameter in target lesions by RECIST on survival of patients with metastatic colorectal cancer. Jpn J Clin Oncol. 2008;38(10):689-94

34. Maurel J, Nadal C, Garcia-Albeniz X, Gallego R, Carcereny E, Almendro V et al. Serum matrix metalloproteinase 7 levels identifies poor prognosis advanced colorectal cancer patients. Int J Cancer. 2007;121(5):1066-71.

35. Mekenkamp $\sqcup$, Heesterbeek KJ, Koopman M, Tol J, Teerenstra S, Venderbosch S, et al. Mucinous adenocarcinomas: poor prognosis in metastatic colorectal cancer. Eur J Cancer. 2012;48(4):501-9. doi:10.1016/j.jca.2011.12.004. Epub 2012 Jan 4.

36. Philipp AB, Nagel D, Stieber P, Lamerz R, Thalhammer I, Herbst A, et al. Circulating cell-free methylated DNA and lactate dehydrogenase release in colorectal cancer. BMC Cancer. 2014;14(1):743.

37. Rambach L, Bertaut A, Vincent J, Lorgis V, Ladoire S, Ghiringhelli F. Prognostic value of chemotherapy-induced hematological toxicity in metastatic colorectal cancer patients. World J Gastroenterol. 2014;20(6):1565-73.

38. Sastre J, Marcuello E, Masutti B, Navarro M, Gil S, Anton A, et al. Irinotecan in combination with fluorouracil in a 48-hour continuous infusion as first-line chemotherapy for elderly patients with metastatic colorectal cancer: A Spanish Cooperative Group for the Treatment of Digestive Tumors study. J Clin Oncol. 2005:23(15):3545-51.

39. Scartozzi M, Giampieri R, MacCaroni E, Del Prete M, Faloppi L, Bianconi M, et al. Pre-treatment lactate dehydrogenase levels as predictor of efficacy of first-line bevacizumab-based therapy in metastatic colorectal cancer patients. Br J Cancer. 2012;106(5):799-804.

40. Shah U, Pendurti G, Swami U, Hou Y, Ghalib MH, Chaudhary I, et al. Clinical outcome for patients with metastatic colorectal cancer (mCRC) enrolled in phase I clinical trials: Single institution experience. J Clin Oncol 2013;31(15).

41. Shitara K, Yuki S, Yamazaki K, Naito Y, Fukushima H, Komatsu Y, et al. Validation study of a prognostic classification in patients with metastatic colorectal cancer who received irinotecan-based second-line chemotherapy. J Cancer Res Clin Oncol. 2013;139(4):595-603.

42. Suenaga M, Matsusaka S, Takagi K, Kuboki Y, Watanabe T, Shinozaki E, et al. Potential markers predicting bevacizumab efficacy for metastatic colorectal cancer patients. J Clin Oncol 2010;28(15).

43. Tol J, Koopman M, Cats A, Rodenburg CJ, Creemers GJ, Schrama JG, et al. Chemotherapy, bevacizumab, and cetuximab in metastatic colorectal cancer. N Engl J Med. 2009;360(6):563-72. doi:10.1056/NEJMoa0808268.

44. Uysal M, Bozcuk H, Sezgin Goksu S, Murat Tatli A, Arslan D, Gunduz S, et al. Basal proteinuria as a prognostic factor in patients with metastatic colorectal cancer treated with bevacizumab. Biomed Pharmacother. 2014;68(4):409-12.

45. Van Cutsem E, Bajetta E, Valle J, Kohne $\mathrm{CH}$, Hecht JR, Moore M, et al. Randomized, placebo-controlled, phase III study of oxaliplatin, fluorouracil, and leucovorin with or without PTK787/ZK 222584 in patients with previously treated metastatic colorectal adenocarcinoma. J Clin Oncol. 2011;29(15):2004-10.

46. Wiggers T, Arends JW, Volovics A. Regression analysis of prognostic factors in colorectal cancer after curative resections. Dis Colon Rectum. 1988;31(1):33-41.

47. Yin C, Jiang C, Liao F, Rong Y, Cai X, Guo G, et al. Initial LDH level can predict the survival benefit from bevacizumab in the first-line setting in Chinese patients with metastatic colorectal cancer. Onco Targets Ther. 2014;7:1415-22. doi:10.2147/OTT.S64559. eCollection 2014. 
48. Bar J, Spencer S, Morgan S, Pike L, Cunningham D, Robertson JD, et al. Correlation of lactate dehydrogenase $(\mathrm{LDH})$ isoenzyme profile with outcome in advanced colorectal cancer (CRC) patients (pts) treated with chemotherapy and bevacizumab (BEV) or cediranib (CED). J Clin Oncol 2012;30(15).

49. Bidard FC, Tournigand C, Andre T, Mabro M, Figer A, Cervantes A, et al. Efficacy of FOLFIRI-3 (irinotecan D1, D3 combined with LV5-FU) or other irinotecan-based regimens in oxaliplatin-pretreated metastatic colorectal cancer in the GERCOR OPTIMOX1 study. Ann Oncol. 2009;20(6):1042-7.

50. Chibaudel B, Tournigand C, Artru P, Andre T, Cervantes A, Figer A, et al. FOLFOX in patients with metastatic colorectal cancer and high alkaline phosphatase level: An exploratory cohort of the GERCOR OPTIMOX1 study. Ann Oncol. 2009;20(8):1383-6.

51. Cierpinski A, Stein A, Russel J, Ettrich T, Schmoll HJ, Arnold D. Prognostic impact of carcino embryonic antigen (CEA), carbohydrate antigen (CA 19-9), and lactate dehydrogenase (LDH) decrease in patients with metastatic colorectal cancer (mCRC) receiving a bevacizumab-or cetuximabchemotherapy combination. Onkologie. 2011;34:250.

52. Diouf M, Bonnetain F, Chibaudel B, Tournigand C, Teixeira L, Marijon H, et al. Could baseline health-related quality of life (QoL) improve prognostication of overall survival in metastatic colorectal cancer? Results from GERCOR OPTIMOX 1 study. J Clin Oncol 2011;29(15).

53. Jain S, Agrawal K, Pattali S, Singh A, Agrawal K, Cleveland B, et al. Multivariate analysis of factors affecting overall survival in minority-based population of young colorectal cancer patients: A single-institution experience. J Clin Oncol 2012;30(15).

54. Maccaroni E, Giampieri R, Scartozzi M, Del Prete M, Faloppi L, Bianconi M, et al. Pretreatment levels of serum lactate dehydrogenase (LDH) and clinical outcome in metastatic colorectal cancer patients receiving first-line chemotherapy and bevacizumab. J Clin Oncol 2012;30(4).

55. Mekenkamp LIM, Heesterbeek CJ, Koopman M, Teerenstra S, Venderbosch S, Punt CJA, et al. Prognostic and predictive value of mucinous adenocarcinomas in colorectal cancer patients treated with chemotherapy and targeted therapy. Eur J Cancer. 2011;47:S396.

56. Mekenkamp LJM, Koopman M, Teerenstra S, Van Krieken JHJM, Mol L, Nagtegaal ID, et al. Clinicopathological features and outcome in advanced colorectal cancer patients with synchronous vs metachronous metastases. Br J Cancer. 2010;103(2):159-64

57. Shitara K, Matsuo K, Yokota T, Takahari D, Shibata T, Ura T, et al. Prognostic factors for metastatic colorectal cancer patients undergoing irinotecan-based second-line chemotherapy. Gastrointestinal Cancer Res. 2011;4(5-6):168-72.

58. Suenaga M, Matsusaka S, Ueno M, Yamamoto N, Shinozaki E, Mizunuma N, et al. Predictors of the efficacy of FOLFIRI plus bevacizumab as second-line treatment in metastatic colorectal cancer patients. Surg Today. 2011;41(8):1067-74.

59. Van Kessel CS, Samim M, Koopman M, Van Den Bosch MAAJ, Borel Rinkes IHM, Punt CJA, et al. Radiological heterogeneity in response to chemotherapy is associated with poor survival in patients with colorectal liver metastases. Eur J Cancer. 2013;49(11):2486-93.

60. Silvestris N, Scartozzi M, Graziano G, Santini D, Lorusso V, Maiello E, et al. Basal and bevacizumab-based therapy-induced changes of lactate dehydrogenases and fibrinogen levels and clinical outcome of previously untreated metastatic colorectal cancer patients: a multicentric retrospective analysis. Expert Opin Biol Ther. 2015;15(2):155-62.

\section{Submit your next manuscript to BioMed Central and we will help you at every step:}

- We accept pre-submission inquiries

- Our selector tool helps you to find the most relevant journal

- We provide round the clock customer support

- Convenient online submission

- Thorough peer review

- Inclusion in PubMed and all major indexing services

- Maximum visibility for your research

Submit your manuscript at www.biomedcentral.com/submit

) Biomed Central 